This item was submitted to Loughborough's Research Repository by the author.

Items in Figshare are protected by copyright, with all rights reserved, unless otherwise indicated.

\title{
Surface cleaning technologies for the removal of crosslinked epoxide resin
}

PLEASE CITE THE PUBLISHED VERSION

PUBLISHER

(C) Elsevier

LICENCE

CC BY-NC-ND 4.0

\section{REPOSITORY RECORD}

Litchfield, Robert E., Gary W. Critchlow, and S. Wilson. 2006. "Surface Cleaning Technologies for the Removal of Crosslinked Epoxide Resin”. figshare. https://hdl.handle.net/2134/861. 


\title{
Surface cleaning technologies for the removal of crosslinked epoxide resin
}

\author{
R.E.Litchfield ${ }^{1}$, G.W.Critchlow ${ }^{1} *$ and S.Wilson ${ }^{2}$ \\ ${ }^{1}$ Institute of Surface Science and Technology, IPTME, Loughborough University, \\ Loughborough, Leicestershire, LE11 3TU, UK \\ ${ }^{2}$ Bombardier Aerospace/Short Bros., Airport Road, Belfast, Northern Ireland, BT3 9DZ, UK \\ *author to whom correspondence should be addressed, g.w.critchlow@lboro.ac.uk
}

Keywords: epoxides, metals, abhesion/non-stick.

\begin{abstract}
This study provides details of the use of laser ablation and sodium hydride cleaning processes for the removal of crosslinked epoxide and other residues from resin transfer moulding (RTM) tool substrates, as used in the aerospace industry. The requirement for removal of such contamination is so that the mould can be re-used, following the subsequent application of an external release agent. These tools are, typically, fabricated from steel, nickel or CFRP composite materials; this paper focuses on the use of nickel substrates. The requirement to clean large surface areas quickly to satisfy commercial restraints, compromises the degree of absolute cleanliness that can be obtained. However, in applications where cleaning time is not a constraint, laser cleaning can be a very gentle and efficient process; typically Nd:YAG lasers find application in this area. In contrast, high power lasers are desirable for industrial scale applications where large areas need to be cleaned quickly. In this instance pulsed $\mathrm{CO}_{2}$ lasers can be used. The use of sodium hydride was also found to be highly successful in removing crosslinked organic contamination providing that suitable hard rinse and drying operations were also carried out.
\end{abstract}

\section{Introduction}

The removal of organic material such as lubricating oils or other processing aids, for example release agents, is routinely carried out as part of most multi-stage metal finishing processes ${ }^{1}$. Commonly, aqueous-based or vapour phase solvent media are used which can effectively remove 
relatively weakly bound organic materials. The aqueous-based media are often combined with agitation including ultrasonics for maximum speed and efficiency.

The current study is, however, concerned with the removal of fully crosslinked organic material from metal surfaces. It is not possible to effectively remove such material using the conventional cleaning procedures referred to above. In particular, this paper focuses on the removal of cured epoxide resin from nickel surfaces using laser ablation. Some consideration of the choice of laser type and laser-coating interactions is contained in this paper as these factors help to explain the experimental results. An alternative process, namely, sodium hydride cleaning will also be discussed although in limited detail. The application of this technology is in the aerospace industry where metal mould tools are used in the production of resin transfer moulding (RTM) components. Occasionally, the tooling requires cleaning to remove residual epoxides from the casting process so that the tools can be re-used following the application of an external mould release system. An additional requirement for a successful cleaning procedure is therefore to create a surface that can accommodate the application of an organic coating. Cured epoxide resins are both cohesively strong and may be attached via mechanical interlocking or chemisorbed onto the nickel.

The removal of residual epoxides from mould tools can be carried out using mechanical methods, for example, sanding or grit-blasting. These methods are both extremely time consuming and induce significant amounts of surface physical damage rendering the moulds more liable to contamination on subsequent usage. Alternatively, industrial scale cleaning solutions may be used incorporating methylene chloride. Current environmental and health and safety legislation are acting as driving forces to identify new cleaning methods that obviate the need for this process.

Within the last decade laser cleaning has emerged as a viable solution to such problems. The use of lasers in conservation and art restoration ${ }^{2}$ is a mature technology but the use of lasers for industrial scale applications, where the time taken to clean and capital equipment costs are critical factors, is only now being fully addressed. The use of laser processing to promote adhesion by surface desorption, deposition and texturing is also recognised but such processes are not directly relevant to the present study ${ }^{3-6}$.

Excimer lasers operating at ultra-violet (uv) wavelengths are successful at processing many organic polymers and are effective in laser cleaning but the relatively high absorptivity of metals at uv wavelengths is a problem where heating or melting effects upon the metal substrate have to be considered. In the current application little or no interaction with the substrate is desirable. A recent novel and successful application of laser cleaning utilising a Nd: YAG (Neodymium: Yttrium 
Aluminium Garnet) laser has been to clean leaves from railway tracks ${ }^{7}$. Although lasers can be used to harden metals by introducing compressive surface stresses, this does not occur under the typical operating conditions used for laser cleaning. In this example, metallurgical tests have shown that no increase in the martensite phase of the steel or other detrimental thermal damage to the railway tracks occurred after more than five billion pulses.

Other applications of laser cleaning include tyre mould refurbishment ${ }^{8}$, although little has been published of relevance to larger industrial scale cleaning of metal moulds and, in particular, to the removal of cured resin from such tooling. Robotically controlled solid-state lasers used in tyre mould cleaning can clean approximately one square metre of surface area within 45 to 60 minutes, representing a very significant improvement on conventional abrasive cleaning methods.

In addition, powerful multi-kilowatt $(\mathrm{kW})$ carbon dioxide $\left(\mathrm{CO}_{2}\right)$ laser systems have been built by the United States military and have been applied to the paint stripping of aircraft. These have reportedly achieved paint stripping rates of 30 to $60 \mathrm{~m}^{2}$ per hour. Commercial systems have been developed operating up to $2 \mathrm{~kW}$ and have proved highly successful ${ }^{9}$. Stripping of paint from aircraft is periodically necessary to allow metallurgical inspection for metal fatigue. Both these examples represent expensive cleaning solutions and require bespoke designs. To be competitive with other cleaning methods such as dry ice pellet cleaning ${ }^{10,11}$ or high-pressure water jet systems, any laser cleaning solution must be very reliable and competitively priced.

The efficiency of mould release is another factor of importance in the aerospace industry and the adhesion of any applied mould release agent is reliant on obtaining a clean tool surface. Many studies have shown that surface cleanliness promotes good coating adhesion.

Laser cleaning of large surface areas presently utilises TEA (Transversely Excited Atmosphere) $\mathrm{CO}_{2}$ lasers possessing multi-kilowatts energy outputs. These are pulsed lasers that can clean large areas quickly. Carbon dioxide lasers are an obvious choice since the laser output wavelength of 10.6 micrometres $(\mu \mathrm{m})$ couples very effectively to the molecular vibrational modes of many organic materials causing them to heat up and degrade. An organic resin should, therefore, readily absorb energy at this wavelength. Metal substrates are also highly reflective to this laser wavelength with the consequence that the cleaning process is self-limiting with only the organic contaminant being removed. TEA $\mathrm{CO}_{2}$ lasers require separate gas supplies to operate. Sealed radio frequency excited $\mathrm{CO}_{2}$ lasers are an alternative that do not require gas supplies and their reduced physical size makes them more suitable for robotic mounting. These systems though are not as powerful as TEA $\mathrm{CO}_{2}$ lasers and the intended market for them is biased towards materials processing rather than cleaning 
applications. Shorter wavelength lasers such the Nd:YAG solid state laser are also available for cleaning and find greatest application in art restoration work but the reflectivity of metals falls off at shorter wavelengths so that there is a greater chance that some substrate damage may occur when they are used to remove coatings from metals.

Most applications of $\mathrm{CO}_{2}$ lasers utilise $\mathrm{CNC}$ tables to move the work-piece requiring cleaning with the laser being either static or mounted on a robot arm; with appropriate control over the arm the laser is scanned over the area to be cleaned. Where the cleaning of very large moulding tools is considered, the workpiece cannot be moved and some form of automation is required to scan the laser over the area to be cleaned. The physical size of a TEA $\mathrm{CO}_{2}$ laser would suggest that this option would be costly to implement and not very flexible. Aside from the cost issues involved in realising an industrial scale laser cleaning solution with $\mathrm{CO}_{2}$ lasers, the technology has some other disadvantages. At present, there exist few materials that will transmit the $10.6 \mu \mathrm{m}$ wavelength without significant absorption. The main exceptions are zinc selenide or germanium and focussing optics have to be produced from these rather exotic materials. Highly polished mirrors made from gold or copper can also be used because of the high reflectivity of metals at $10.6 \mu \mathrm{m}$. Unlike $\mathrm{CO}_{2}$ lasers used for cutting and welding processes, where optics focus the laser light down to very small spot sizes, laser cleaning requires defocused beams covering an area of a few square centimetres.

Ideally, the energy distribution across such beams should be uniform but this is difficult to achieve because of the way high power $\mathrm{CO}_{2}$ lasers are designed. Measuring laser energy densities (or fluences) for intense lasers poses experimental problems since conventional power meters used for most other laser power measurements are very easily damaged by high-energy pulses and very expensive to replace. Such measurements are desirable to optimise any cleaning process but are difficult to make and estimated measurement errors of $\pm 10 \%$ or more are common. Other critical factors are the pulse duration and repetition rate. A minimum (or threshold) intensity is required to thermally ablate any contaminant layer and this is a function of the material composition.

Despite a greater propensity to cause thermal damage on metal substrates due to the reduced reflectivity, the use of Nd:YAG lasers, operating at an output wavelength of $1.06 \mu \mathrm{m}$, offers some distinct advantages. Glass fibre optic beam delivery from the laser source to the work piece is possible because there is very little absorption by the glass at this wavelength. This greatly enhances the flexibility of the cleaning process since a skilled operator can now manoeuvre a hand held laser cleaning head over the area to be cleaned and if necessary simply increase the fluence to remove stubborn contamination. The use of a solid-state laser also makes the laser inherently more reliable and free from operating faults. The technology of these lasers is well developed. Unlike 
TEA $\mathrm{CO}_{2}$ lasers, which are physically bulky systems requiring gas and three phase electrical power supplies the size of Nd:YAG systems has been steadily reduced and current small footprint units are marketed. These advantages are made at the sacrifice of cleaning rates which are slower than using $\mathrm{CO}_{2}$ lasers but still competitive with other non-laser cleaning methods. In most other respects $\mathrm{Nd}$ :YAG lasers offer the most cost effective laser cleaning solution.

Paint stripping applications are also possible using relatively small, compact diode laser arrays where power outputs can be as high as $5 \mathrm{~kW}$. Using oxygen assist gas, it has been reported that a $120 \mathrm{~W}$ diode laser was capable of removing thick coatings of white, chlorinated rubber paint from concrete surfaces at cleaning rates of several square metres per hour. However, an oxygen assist gas was used to affect a controlled combustion and it is conjectured that this would be unsuitable for coating removal from most metal substrates.

One drawback of laser cleaning is that it is largely a line-of-sight technique and has difficulty in cleaning very complex shaped mould tooling. In such cases there is little alternative but to resort to a chemical cleaning method where the tool is lowered into a bath of cleaning agent. In these applications it is also desirable that the cleaning chemistry used removes silicones arising from degraded mould release agents as well as crosslinked epoxide resin. The chemical inertness of silicones requires aggressive and very searching cleaning agents that will not damage the metal substrate. One technology that will fulfil these requirements is the use of a fused alkali bath. Aside from the toxicity and high operating temperature of this process, no other solvents are involved and so waste is kept to a minimum. There is, however, a practical size limitation on the tooling that is amenable to this cleaning method. For reasons that will be discussed the process is best suited to nickel or metals that are not susceptible to rapid rusting once a clean surface has been obtained.

DuPont developed a sodium hydride treatment in $1942^{12}$ as a method for removing oxide scale and casting sand residues from metal castings using a fused alkali bath, which would not cause any damage to the casting. The process has been described in detail by Lightfoot ${ }^{13}$. Lightfoot applied the sodium hydride process to the destruction of toxic chlorinated organic compounds.

The process itself requires the part to be immersed in a molten bath of anhydrous sodium hydroxide maintained at $360^{\circ} \mathrm{C}$. Hydrogen is passed through the melt to create a relatively dilute $2 \%$ solution of sodium hydride. The sodium hydride is a very powerful reducing agent capable of removing most metal oxides and exposing the bare metal. Refractory oxides such as those of aluminium, titanium or silicon are not reduced but are removed by conversion to the corresponding elemental silicates by the highly basic anhydrous melt. Unlike conventional acid pickling solutions the 
substrate metal is not attacked by this highly basic medium provided the metal is immediately quenched in a large excess of clean water upon removal from the melt. Many steels cleaned in this way would rapidly rust in the time taken to move them to any oven for drying and so it is suggested that the process is better suited to metals such as nickel. The very low surface tension of the melt renders the treatment extremely searching penetrating into any hairline cracks or the interfacial regions between any coating and the metal. Combined with the high temperature of the melt, and net action on any organic coatings such as resins would be to carbonise them and pressure washing is necessary to remove carbonised organic residues from the metal surface.

Sodium hydride cleaning has the advantage of being one of very few methods that will remove any silicone contamination from a metal surface. Cleaning time is relatively quick but the process is obviously hazardous although process controls and containment can be achieved.

In summary, the there are a number of technological issues which make the removal of fully crosslinked epoxide resin from rough metal surfaces difficult to achieve. This is particularly difficult if this is to be achieved with minimum interaction with the underlying substrate. In the present study, two options: laser ablation, and; sodium hydride treatment will be considered for the removal of epoxide resin from nickel substrates.

\section{Experimental}

\subsection{Materials}

Coupons of nickel plate, measuring $5 \mathrm{~cm}$ x $5 \mathrm{~cm}$ x $5 \mathrm{~mm}$ thickness, were used as substrates for the bonding of epoxide resin. Surfaces were mechanically scoured using abrasive pads to produce a roughness measurement $\left(\mathrm{R}_{\mathrm{a}}\right)$ of $0.405 \mu \mathrm{m}$. The following cleaning regime was then applied.

Coupons were initially doubly-degreased using ultrasonic agitation in super-purity acetone. These were then immersed in boiling aqueous alkaline cleaner (Isoprep 44) with mechanical agitation for a period of 30 minutes. Each sample was then rinsed in running hot tap water and transferred to a fresh solution of the alkaline cleaner which was at room temperature. Samples were then subjected to ultrasonic agitation for a further 30 minutes before each was again rinsed in hot tap water and thoroughly dried in an oven at $120^{\circ} \mathrm{C}$ for 60 minutes.

An average water contact angle of $32^{\circ}$ was measured for the nickel samples following this treatment. This suggested the nickel samples were reasonably clean. Note that clean metal surfaces 
attract a thin layer of contamination very quickly and measured contact angles rapidly increased to $50^{\circ}$ and above. Surface roughness is also a factor affecting contact angles and the same cleaning regime applied to a smoother stainless steel foil resulted in values between $10^{\circ}$ and $20^{\circ}$.

The epoxide resin system used to coat the samples was Hexcel RTM6. This was warmed to reduce its viscosity, a quantity was then thoroughly mixed with an equal volume of acetone which was used as a solvent. This solution was then brushed onto cleaned metal coupons. After a single application the coupon was cured for 4 hours in an oven at $180^{\circ} \mathrm{C}$. thickness measurements from coupons after cooling of the cured resin showed the resin thickness to be within the range 100 to $150 \mu \mathrm{m}$, the greater thickness occurring towards the edge of the samples.

\subsection{Laser Cleaning}

A study of the effects of $\mathrm{CO}_{2}$ lasers on resin coated nickel tooling was performed using a Laserbrand $\mathrm{L} 450 \mathrm{TEA} \mathrm{CO}_{2}$ laser, emitting $10.6 \mu \mathrm{m}$ radiation in a $100 \mathrm{~ns}$ pulse of $2 \mathrm{~J}$ output energy. The unfocussed beam is approximately square with an area of $10 \mathrm{~cm}^{2}$ which was focussed down to $1 \mathrm{~cm}^{2}$ using a plano-convex $\mathrm{ZnSe}$ lens of focal length $30 \mathrm{~cm}$. At this area the fluence is great enough to readily vaporise organic coatings. Coated metal samples were then positioned at various distances from the focus to receive differing fluences. The samples were all mounted such that the laser beam was incident normal to the surface of the coated samples. This was done to eliminate angle of incidence as a variable and simplify evaluation. The number of pulses required to produce a visible effect on the coating for a given fluence was noted. With smaller, much lighter samples a sensitive mass balance could be used to monitor weight loss as the coating was removed but this was considered to be impractical in this study.

Generally, it has been found that cleaning fluences range from 1 to $4 \mathrm{~J} . \mathrm{cm}^{-2}$ depending on the absorption characteristics of the coating. Higher fluences may be required for weakly absorbing

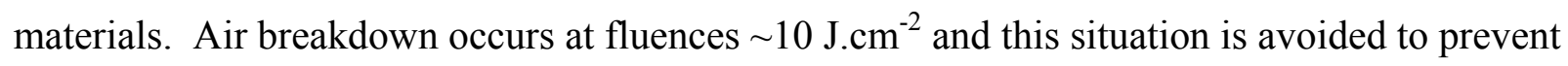
plasma formation, which produces many undesirable secondary effects. Sometimes these plasmas are triggered by the non-removal or ineffective removal of ablated material. Since very high temperatures are a characteristic of plasmas these can radiate sufficient energy to the substrate and induce thermal damage.

The laser cleaning effects obtainable from the lower $1.060 \mu \mathrm{m}$ wavelength radiation from $\mathrm{Nd}: \mathrm{YAG}$ lasers were investigated using a Spectron SL456 pulsed Nd:YAG. The laser utilises a temperature stabilised Pockels cell to effect Q-switching, enabling the laser to produce a short, intense pulse of 
energy (duration 13ns). Output power level and repetition rate were adjusted to give a maximum output of $850 \mathrm{~mJ}$ up to $10 \mathrm{~Hz}$. Repetition rates up to $5 \mathrm{~Hz}$ were used giving pulse energies of approximately $600 \mathrm{~mJ}$, this value being interpolated from the laser's output calibration measurement. The focussed laser beam was powerful enough to bore holes into nickel plate so samples requiring cleaning were again positioned at varying distances from the laser focal point and the coating removal effects noted until an optimum distance was found. This proved to be approximately $50 \mathrm{~mm}$ from laser focus. Using this degree of defocusing the beam diameter was about $8 \mathrm{~mm}$ and a single pulse was sufficient to detach cured resin from the metal substrate to which it was bonded. Ideally, the laser beam used for a cleaning application should be spatially homogenous with a "top-hat" shaped intensity distribution. Laboratory lasers generally do not meet this requirement and in the case of a Nd:YAG laser, may have Gaussian beam profiles more suited to non cleaning applications and materials processing. This consideration is particularly severe with TEA $\mathrm{CO}_{2}$ lasers where the beam is never homogenous and there exists a distribution of fluence over its area. This problem makes it difficult to correlate microstructure observed on treated samples with an accurately known fluence. In the case of Nd:YAG lasers, the manufacturers of a commercial Nd:YAG laser designed for cleaning applications (and possessing a homogenised beam) were approached and some resin coated samples submitted for laser cleaning. These samples were cleaned at a rate of $10 \mathrm{~cm}^{2}$ per second using a fluence of $1 \mathrm{~J} . \mathrm{cm}^{2}$ with normal incidence of the beam. The microstructural topography was found to be comparable to those obtained with the Spectron laser.

\subsection{Sodium Hydride Cleaning}

Resin coated nickel tooling was immersed in a bath containing anhydrous sodium hydroxide with a $2 \%$ addition of sodium hydride maintained at $360^{\circ} \mathrm{C}$ for a period of 60 minutes. After removal the tooling was thoroughly rinsed and stored in absolute ethanol to minimise subsequent oxidation prior to analysis.

\section{Results}

\subsection{Samples cleaned using $\mathrm{TEA} \mathrm{CO}_{2}$ laser ablation}

Figures $1 \mathrm{a}$ and $1 \mathrm{~b}$ show macro photographs of a resin coated nickel plate in which strips of resin have been removed using a laser fluence of $6 \mathrm{~J}_{\mathrm{cm}} \mathrm{cm}^{-2}$. When examined in the scanning electron 
microscope (SEM), the 'cleaned' areas show thin residual patches of resin which are visible as dark areas, see Figure 1c. Areas free from any such residue show a clean surface with no thermal damage to the nickel substrate, see Figure $1 \mathrm{~d}$.

\subsection{Samples cleaned using Nd:YAG laser ablation}

Figures $2 \mathrm{a}$ and $2 \mathrm{~b}$ show macro photographs of a resin coated nickel plate from where detachment of

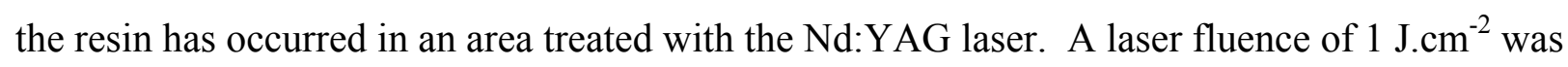
used. Figures $2 \mathrm{c}$ and $2 \mathrm{~d}$ show SEM images of the cleaned substrate beneath the detached resin. The substrate is exceptionally clean. The scratches originate from the abrasive scouring of the samples prior to resin bonding. Figure $2 \mathrm{~d}$ shows that some slight thermal damage has occurred due to the greater absorption of the metal substrate for $\mathrm{Nd}$ :YAG radiation of $1.060 \mu \mathrm{m}$ wavelength. It is argued that this damage is inconsequential compared to that produced by abrasive cleaning procedures.

Auger electron spectroscopy (AES) was used to determine the level of residual surface contamination on the laser cleaned sample. Argon ion bombardment was used to determine subsurface compositions and an empirical etch rate was applied to enable depth scale calibration. It was concluded from AES that the thickness of surface contamination following laser ablation of a $150 \mu \mathrm{m}$ coating of resin was only approximately $5 \mathrm{~nm}$. This demonstrates the effectiveness of the $\mathrm{Nd}$ :YAG process in this application. A water contact angle of $38^{\circ}$ was obtained for the freshly cleaned nickel surface following Nd:YAG laser removal of resin.

Where the contamination is resinous but does not form a continuously cohesive film, comprising instead particulate matter with granular texture, laser cleaning using Nd:YAG is still effective. Figure 2e shows that such contamination on nickel is removed leaving a bright metal surface. Upon examination using scanning electron microscopy, the contrast between a cleaned and uncleaned area is marked. The mechanism of detachment in this case is more complex and less easy to interpret.

\subsection{Samples cleaned using the sodium hydride process}

Figure $3 \mathrm{a}$ is a macro photograph showing a resin coated nickel sample adjacent to one that has been treated using the sodium hydride process. This process was shown to chemically reduce any organic material present to a black char which is easily removed using a water jet provided this is 
done immediately following treatment. Following such treatment a bright metal surface is revealed and visual inspection shows no trace of any resin residue. Water contact angle measurements gave an average angle of $40^{\circ}$ but the surface rapidly contaminated by absorption from the atmosphere. Examination of such a cleaned surface using scanning electron microscopy reveals only the scratches from abrasive scouring prior to bonding of the resin, see Figures $3 b$ and $3 c$.

By using energy dispersive X-ray microanalysis (EDXA), the elemental composition of the cleaned surface is revealed, see Figure $3 \mathrm{~d}$, this shows only trace levels of elemental impurities below the main intense peaks associated with nickel. The most likely source of these impurities is from samples previously cleaned using the process since a commercial metal finishing bath was used.

Again, AES was used to confirm the surface cleanliness, in this case the thickness of the residual surface contamination was found to be approximately $30 \mathrm{~nm}$. Although thicker than that obtained by laser cleaning the level of contamination is slight and relatively inconsequential for industrial applications.

\section{Discussion}

The mechanism of RTM6 epoxide coating removal varies depending on the pulse duration. Considering a general coating such as a multi-layer paint, irradiation by high-energy pulses in the order of a few milliseconds will burn the coating but may also affect the substrate if there is sufficient for heat conduction to occur by thermal diffusion.

Lasers used for cutting and welding of metals operate with very long pulse durations of several hundred milliseconds and at high repetition rates. In comparison, shorter nanosecond pulses will not allow any heat transfer to occur to the substrate. When incident on a coating above threshold fluence, these short intense pulses will instantly vaporise the surface layer creating a rapidly expanding cloud resulting in a mechanical shock wave that propagates through the coating and is reflected back from the substrate. The surface pressures created are in the order of kilobars and are more than sufficient to spontaneously eject whole layers of surface coating, apparently overcoming any interfacial forces associated with the adhesion of the coating. The cleaning mechanism in this instance is thermomechanical resulting in detachment of the coating from the substrate as opposed to an ablative process dominated by thermal vaporisation. The shock waves from this thermomechanical effect are audible and can be very loud initially. The intensity of acoustic shock waves can be used to determine when the coating has been removed since their intensity falls as an increasing number of pulses are applied to the same area. A plume of ablated material is usually seen when these short high-energy pulses interact with a surface coating. 
The absorption coefficient of a coating for the wavelength of the incident radiation and those of the substrate are superimposed on the aforementioned processes and if the coating has fillers and other constituents, these will absorb differently. The absorption coefficient will also be affected by the colour of the sample and its surface roughness and texture. The coating thickness can also have effect and this rapidly leads to a very complex multi-variable interaction between the laser and the coating. Both the reflectivity and thermal diffusivity of the substrate are functions of temperature and so, taken in combination, a full description of the mechanisms involved in laser cleaning is a daunting exercise.

In practice, laser cleaning applications have to be optimised for the removal of a specific coating. If applied to other coatings (with different optical and material properties), cleaning may still be possible but some operating parameters such as fluence might need to be increased or a lower cleaning rate accepted. Cleaning rate is largely a function of the average power of the laser output that has to be high. Lasers used for metal cutting and welding have high average powers because they are effectively continuous wave lasers. In contrast the high average power of a cleaning laser requires that the short duration pulse possesses a very high peak power.

For effective laser cleaning it is necessary to remove vaporised material as this might otherwise absorb sufficient radiation to become ionised and form opaque plasma, effectively shielding the target from the remaining laser pulse. Usually a filtered vacuum line is coupled to the laser head to effect efficient removal.

The importance of absorption coefficient $(\alpha)$ has been mentioned. Considering the simple case of an unfilled resin assumed to possess a single absorption coefficient, if the resin strongly absorbs a given incident laser wavelength the coefficient will be high. The penetration depth (L), a more practical measure of attenuation, will consequently be very small $\left(\mathrm{L}=\alpha^{-1}\right)$. Conversely for a weak absorber the penetration depth is significantly greater. Roberts ${ }^{14}$ has studied the interaction of $\mathrm{Nd}$ :YAG and TEA $\mathrm{CO}_{2}$ lasers with epoxy resin and found that $\mathrm{L} \sim 20 \mu \mathrm{m}$ for $\mathrm{CO}_{2}$ lasers operating at $10.6 \mu \mathrm{m}$ wavelength whereas for Nd:YAG lasers operating at $1.064 \mu \mathrm{m}, \mathrm{L} \sim 100 \mu \mathrm{m}$.

If the effective penetration depth into the material (at the laser wavelength) is much smaller than the contaminant coating thickness (d), i.e. $\mathrm{L}<<\mathrm{d}$, then removal of the coating by laser interaction is an ablative process and in the case of a TEA $\mathrm{CO}_{2}$ laser this will involve mainly thermal vaporisation. However when $\mathrm{L} \sim \mathrm{d}$, physical detachment of the resin from the shock wave caused by the laser interaction, will assume a greater role. 
In practical terms this means than a TEA $\mathrm{CO}_{2}$ laser will strip a thick layer of contamination more effectively than a very thin layer and observation supports this. For example an epoxy resin sheet approximately $150 \mu \mathrm{m}$ thick was easily ablated after a few pulses from a TEA $\mathrm{CO}_{2}$ laser in the laboratory whereas a very thin layer cast from solution of the same resin was much more difficult to remove. In the latter cast most of the energy of each laser pulse was reflected back from the metal substrate and so many more pulses were required to remove a very thin contaminant layer.

With Nd:YAG lasers, detachment appears to be the dominant mechanism for removal of resin from the metal substrate. It was observed that a continuous homogenous film of cured epoxy resin (150 $\mu \mathrm{m}$ thick) simply flaked away from the substrate it had adhered to after laser treatment. In other words the adhesive bonds at the metal/oxide interface were completely broken by the intense shock wave and the cohesiveness of the epoxy film meant that large surface areas could be removed with relatively gentle suction. For a less homogenous coating of epoxy resin with granular texture, the same detachment or spallation process occurs but the removal is less dramatic and stronger suction is required to prevent ejected material from depositing back onto and adhering to the cleaned surface.

The absorption characteristics of a metal oxide are different from the parent metal and if the resin is bonded to a thick oxide layer, removal of the resin will expose the oxide to the energy of the laser pulse. Using X-ray photoelectron spectroscopy to examine the underside of a flake of detached resin (resulting from Nd:YAG laser cleaning of epoxy resin bonded to a mild steel substrate) traces of the metal oxide were detected implying that the oxide is partially ablated once exposed to the beam energy. The behaviour of the same metal oxide upon exposure to a high-energy pulse from a TEA $\mathrm{CO}_{2}$ laser is markedly different. In this case the oxide is not shielded from the high temperature plasma, sitting above the irradiated sample, by the resin, since this has been removed by thermal vaporisation. Examination of the oxide using scanning electron microscopy shows innumerable very tiny pits in the oxide surface and it is conjectured that radiated heat from the plasma melts the metal oxide and that absorbed gases present in the oxide migrate to its surface. These become effectively frozen into the surface once laser treatment ceases and that rapid cooling of the molten surface causes micro-cracks to form.

\section{Conclusions}

A review of the literature reveals that the removal of fully crosslinked material from metal surfaces cannot be easily achieved using established cleaning technologies. However, both laser ablation 
and sodium hydride-based processes can be optimised to achieve this result as demonstrated by the effective removal of RTM6 from nickel.

Furthermore, an understanding has been gained of the fundamental interaction between different laser types and epoxide resin and the role of the sodium hydride process in enabling coating removal.

\section{References}

1. Sheasby, P.G. and Pinner, R., The Surface Treatment and Finishing of Aluminium and Its Alloys $6^{\text {th }}$ Ed. Vols $1 \& 2$, Finishing Publications Ltd, 2001.

2. Cooper, M., Laser Cleaning in Conservation, Butterworth Heinemann 1998.

3. Critchlow, G.W., Cottam, C.A., Brewis, D.M and Emmony, D.C., Int.J.Adhesion \& Adhesives, 1997, 17, 143.

4. Gendler, Z., Rosen, A., Bamberger, M., Rotel, M, Zahavi, J, Buchman, A. and Dodiuk, H, J.Materials Sci., 1994, 29, 1521.

5. Broad, R., French, J. and Sauer, J., Int.J.Adhesion \& Adhesives, 1999, 19, 193.

6. Sancaktar, E., Babu, S.V., Zhang, E., D’Couto, G.C. and Lipshitz, H., J.Adhesion, 1995, 50, 103.

7. Physics World Digest May 2002.

8. Butcher, E., Mould Cleaning with Laser Radiation, Kunstoffe Plaste Europe, 1999, 89.

9. Industrial $2 \mathrm{KW} \mathrm{TEA} \mathrm{CO}_{2}$ laser for paint stripping of aircraft. G.Schweizer, L.Werner. SPIE Vol 2502/57.

10. Elbing, F., Anagreh. N., Dorn, L. and Uhlmann, E., Int.J.Adhesion \& Adhesives, 2003, 23(1), 69.

11. D.M.Brewis, G.W.Critchlow and C.A.Curtis, ., Int.J.Adhesion \& Adhesives, 1999, 19, 253

12. DuPont Patent Specification Oct $16^{\text {th }} 1942$ no $14502 / 42(565,567)$.

13. Lightfoot, I.P., Reductive Destruction of Chlorinated Organics in Molten Salts, PhD Thesis, De Montfort University, 2000.

14. Roberts, E., National Laser Centre of South Africa, Private communication. 


\section{Figure Captions}

Figure1 a. to show areas of RTM6 coating removal on a nickel piece $(5 \times 5 \mathrm{~cm})$ following TEA $\mathrm{CO}_{2}$ laser ablation. The dark (brown) areas are RTM6 deliberately left intact for comparative purposes.

b. as a. at higher magnification.

c. Backscatter image of a nickel piece following $\mathrm{TEA} \mathrm{CO}_{2}$ laser ablation. The dark (black) areas are residual islands of RTM6.

d. SEM image of a nickel piece following TEA $\mathrm{CO}_{2}$ laser ablation.

Figure 2 a. to show areas of RTM6 coating removal on a nickel piece $(5 \times 5 \mathrm{~cm})$ following Nd:YAG laser ablation. The areas irradiated/of detachment are clearly visible.

b. as a. at higher magnification.

c. SEM image of a nickel piece following Nd:YAG laser ablation.

d. as c. with extended treatment and showing evidence of micro-melting.

e. to show the effectiveness of Nd:YAG laser ablation at the removal of a noncontinuous film (lower LH corner irradiated, upper RH corner with contamination intact).

Figure 3 a. to show an untreated RTM6 coated nickel piece(lower LH corner) and a sodium hydroxide treated (upper RH corner) treated piece prior to hard rinsing.

b. and c. SEM images of a nickel piece following sodium hydroxide treatment.

d. EDXA scan of a nickel piece following sodium hydroxide treatment. 

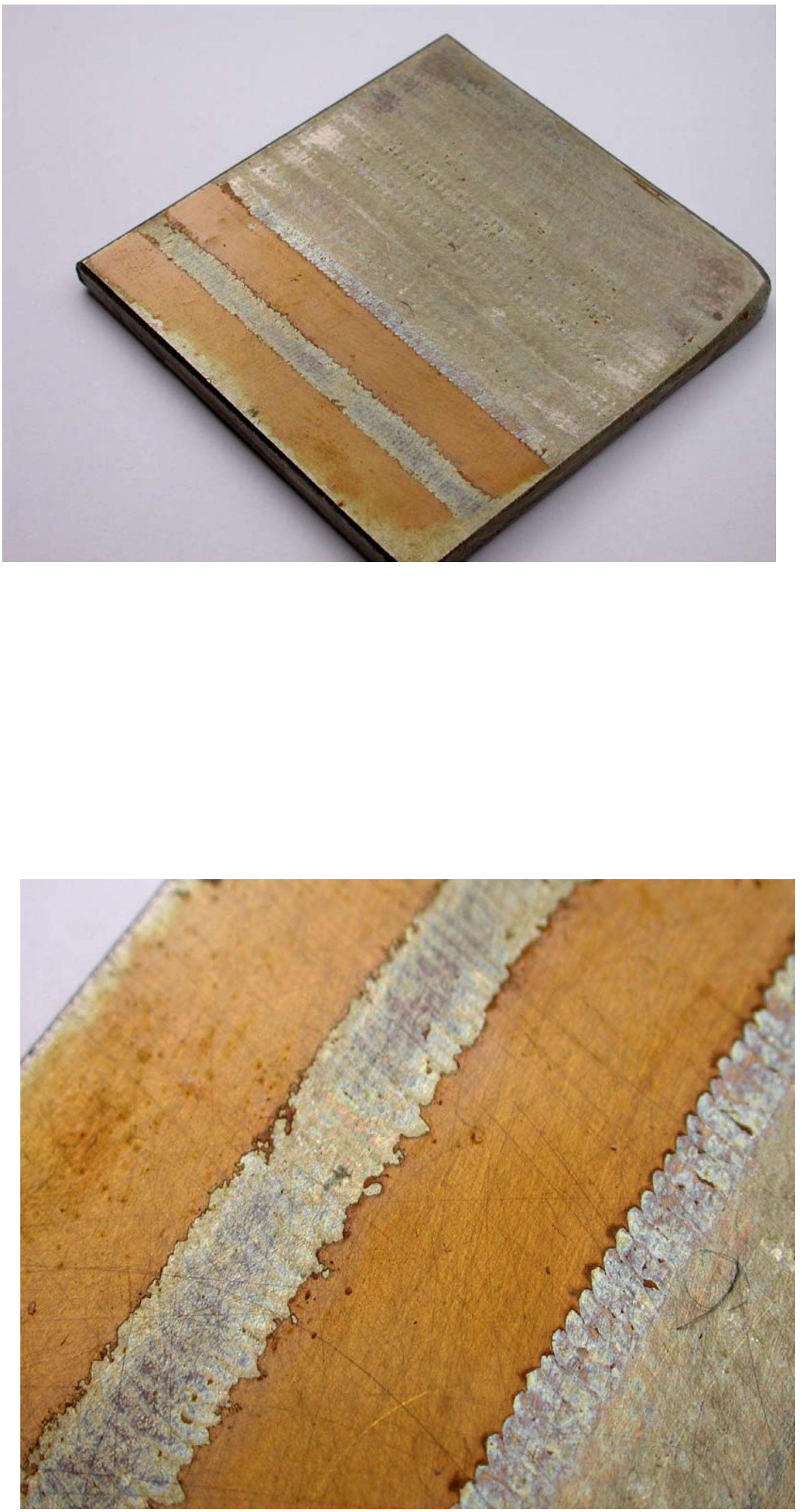

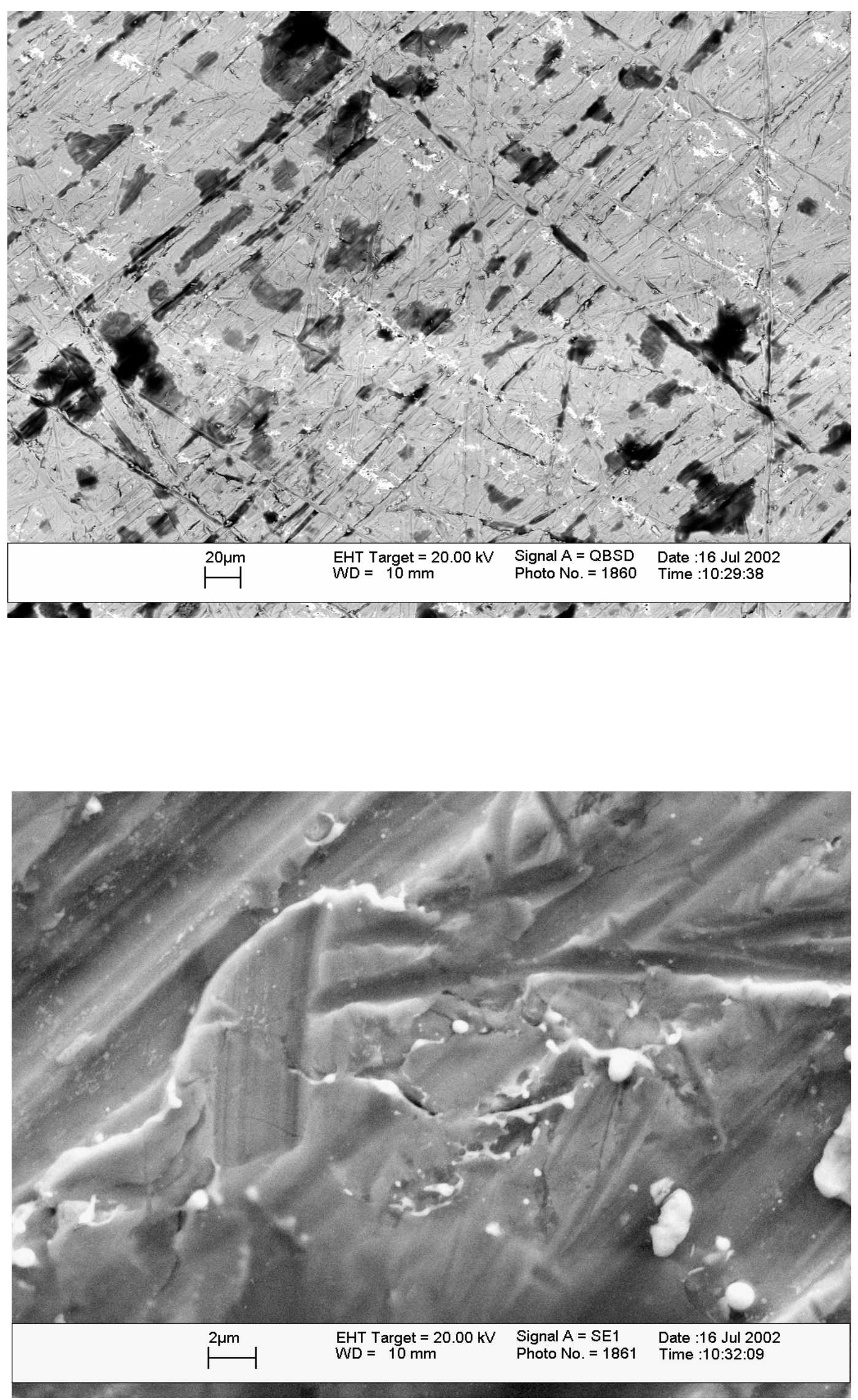

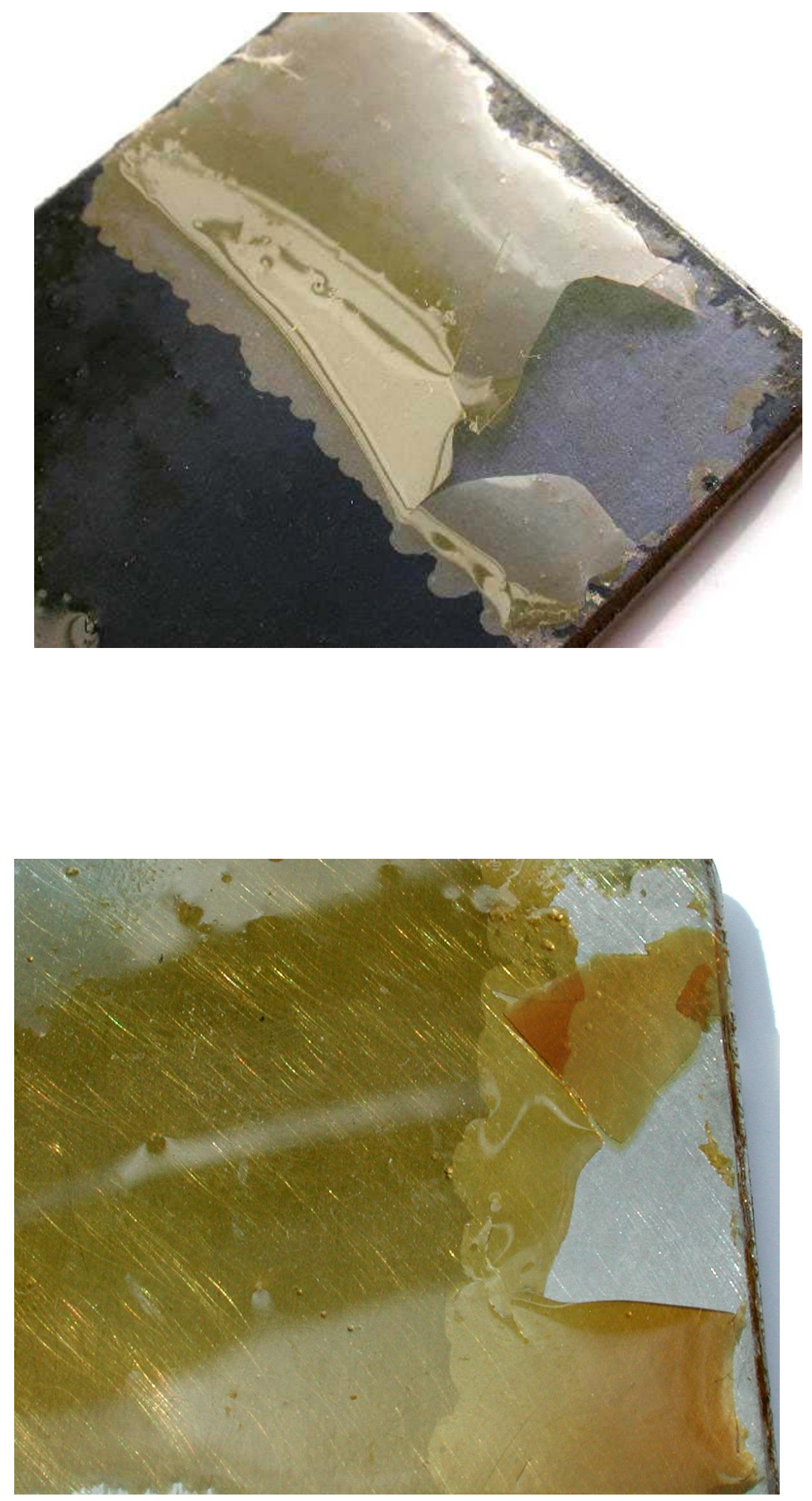

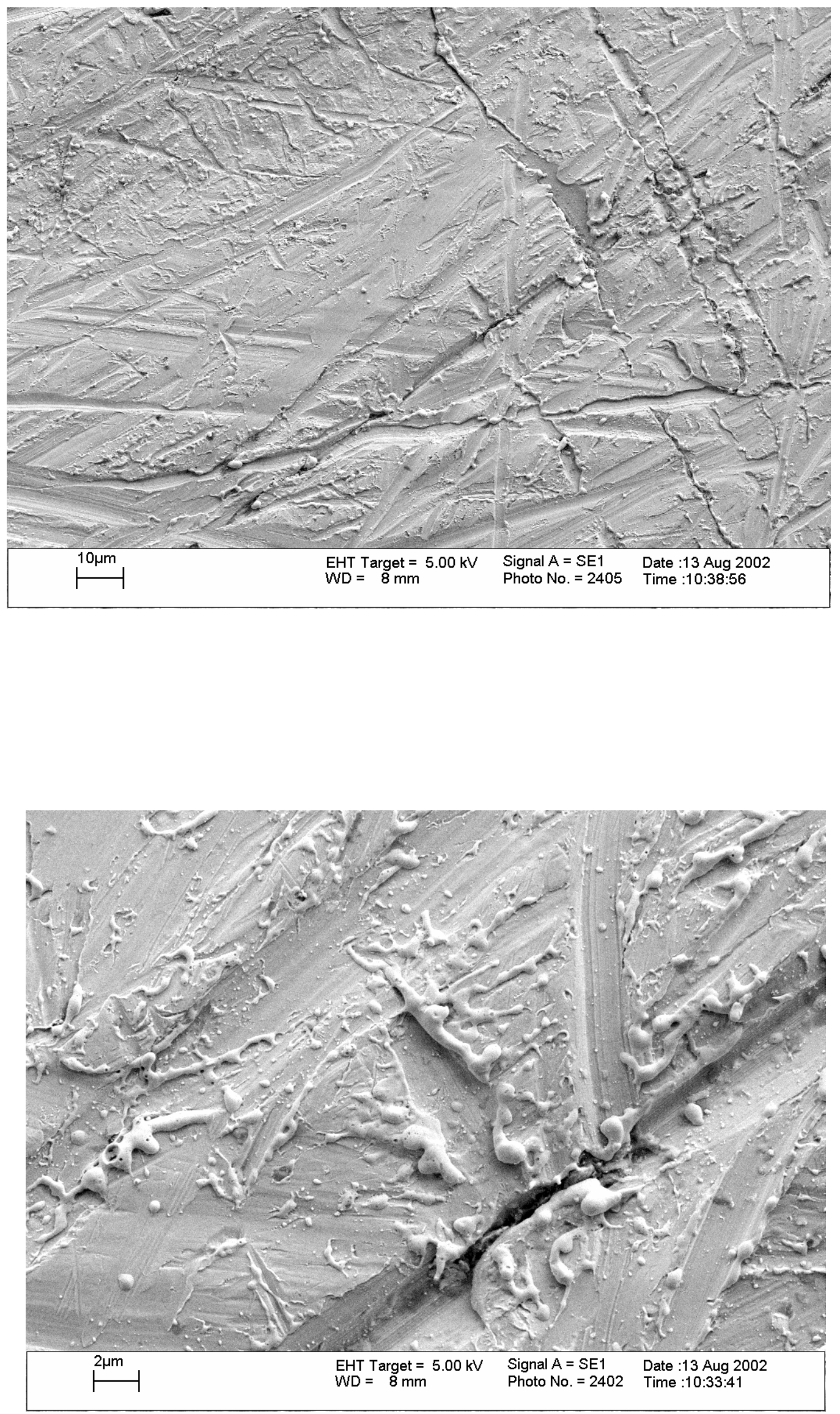
1.
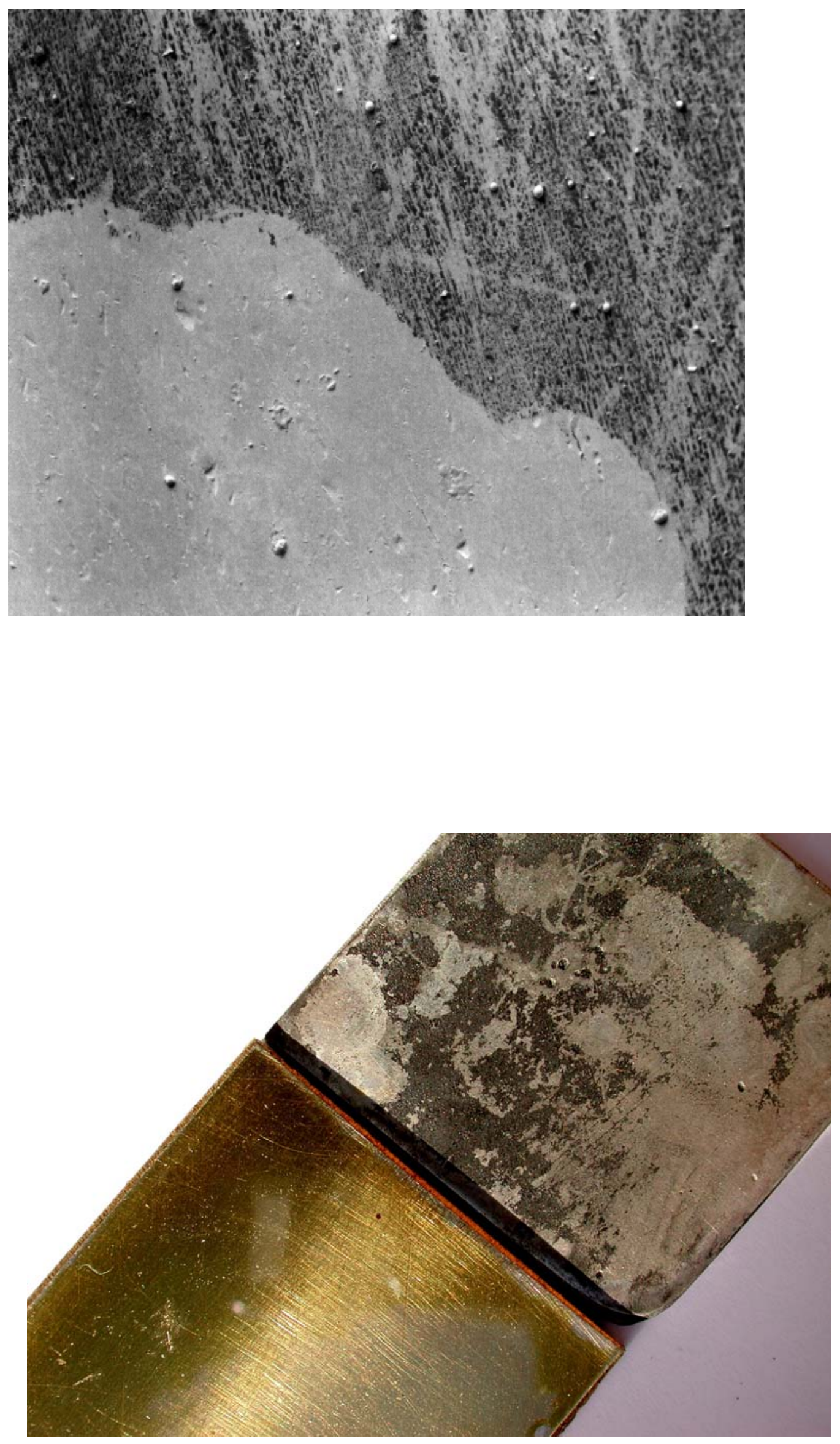

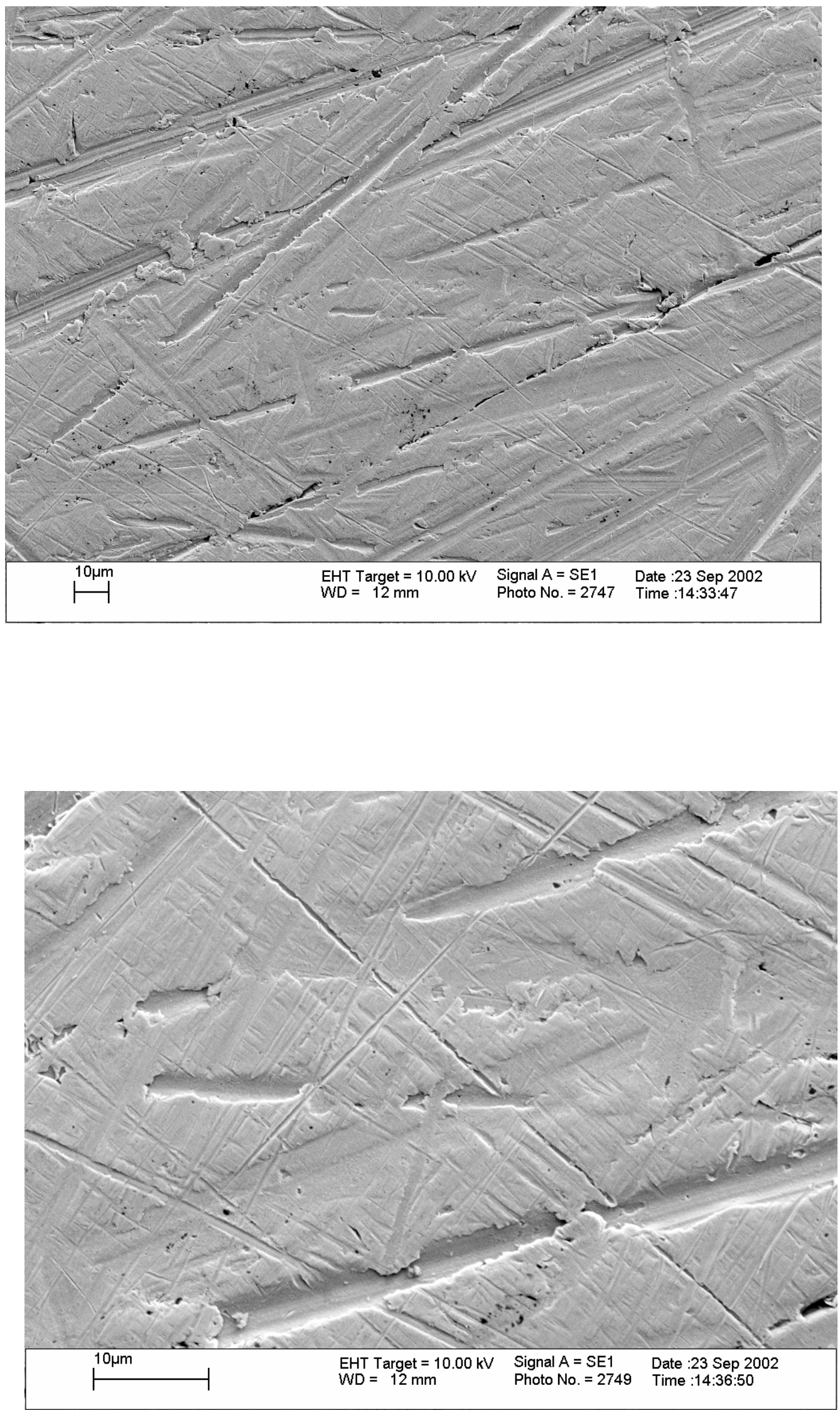


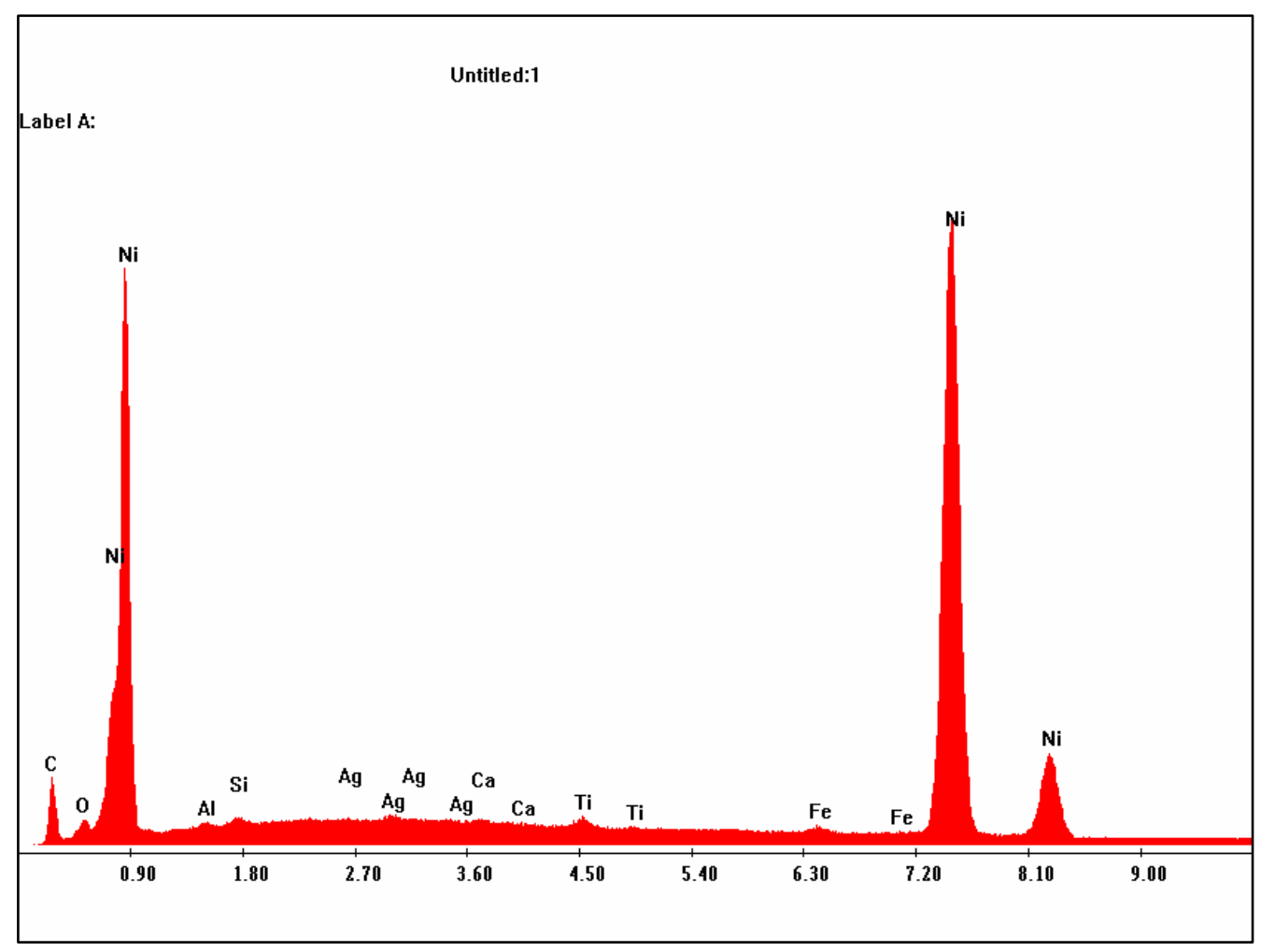

